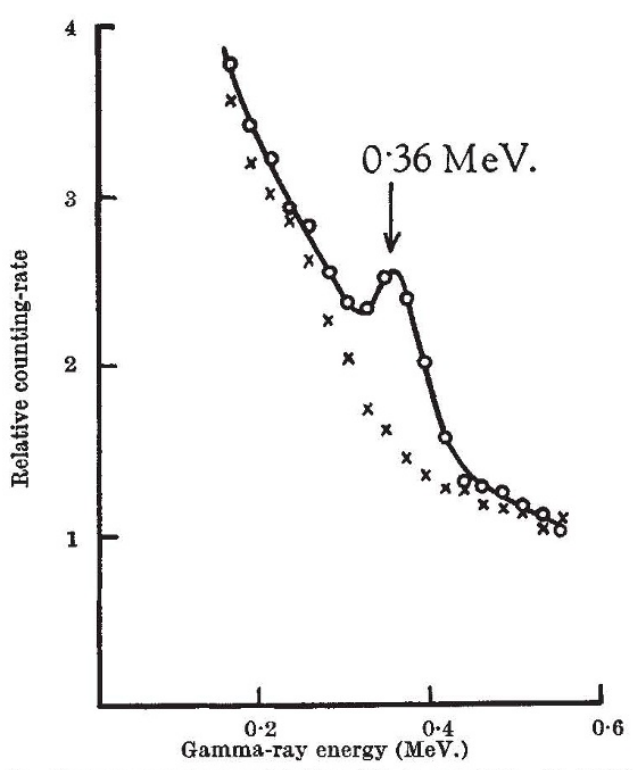

Fig. 2. Gamma spectrum of iodine-131 in rainfall. $O$, Source; $x$, background

to iodine-131 in view of the comparatively short half-lives of the other iodine fission products. A confirmatory measurement on one of the samples was made by $\gamma$-ray spectrometer analysis for iodine-131. Good agreement was obtained, as can be seen in Table 2. The spectrum obtained is shown in Fig. 2.

The confirmatory test of the $\gamma$-ray spectrometer on the second sample yielded a result of $82 \mu \mu \mathrm{c} . / \mathrm{l}$. of iodine-131 compared with $95.5 \mu \mu \mathrm{c}$./1. by $\beta$-analysis.

Although these preliminary results indicate clearly the onset of the Russian testing programme, it is impossible at this stage to attempt a more detailed correlation with individual tests.

I would like to thank Mr. R. A. Pope for measuring the $\gamma$-ray spectra, and the staff of the Radiological Protection Unit for the preparation and analysis of samples. I would like to express my special thanks to Dr. S. E. Hunt for his helpful advice and comments. Thanks are due also to Dr. T. E. Allibone, director of the Laboratory, for permission to publish this communication.

KEITH BODDY

Research Laboratory, Associated Electrical Industries,

Aldermaston Court,

Aldermaston, Berks.

\section{Nuclear Spin of Protoactinium-23I from Hyperfine Splitting}

The nuclear spin of protoactinium was first determined by Schuler and Gollnow in 1934 ${ }^{1}$. They examined the spectrum of protoactinium-231 in the region 4300-5600 $A$. and obtained the nuclear spin $I=\frac{3}{2}$ from hyperfine splitting.

More recently the nuclear spin of protoactinium-233 has been determined ${ }^{2}$ from paramagnetic resonance, and the nuclear spin of tetravalent protoactinium-231 from an investigation of paramagnetic resonance and hyperfine structure ${ }^{3}$. Both authors obtain $I=\frac{3}{2}$.

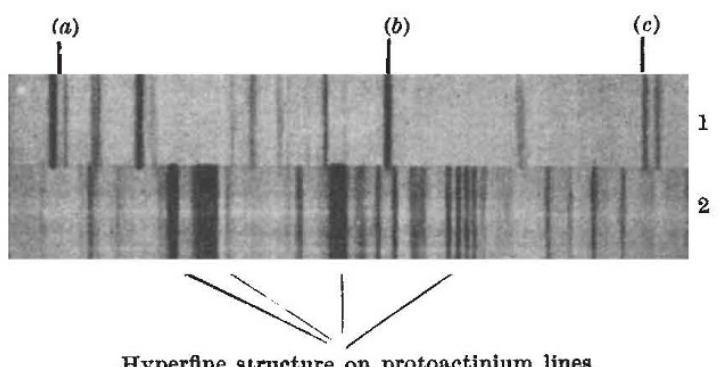

Hyperfine structure on protoactinium lines

Fig. 1. Protoactinium-231 spectrum with thorium comparison

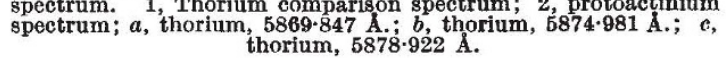

So far, however, the work of Schuler and Gollnow has not been confirmed.

The atomic emission spectrum of protosctinium-231 was recently photographed in the region 4000-9000 A. using the 21 -ft. grating spectrograph at Harwell, and also recorded in the region $0 \cdot 8-2 \cdot 5 \mu$. The light source was an electrodeless discharge tube containing about $3 \mathrm{mgm}$. of protoactinium iodide and excited by microwaves. The spectrum shows pronounced hyperfine structure, the majority of lines being split into four components. This confirms the value $I=\frac{3}{2}$ obtained by previous workers.
E. W. T. RICHARDS
A. Ridgeley
N. J. ATHERTON
H. S. WISE

United Kingdom Atomic Energy Authority, Harwell, Didcot, Berkshire.

${ }^{1}$ Schuler and Gollnow, Naturwiss., 22, 511 (1934).

"Marrus, Nierenberg and Winocur, Nuclear Phys., 28, 1, 90 (1961).

'Axe, Stapleton and Jeffries, Nuclear Phys. Abstr., 15, 3213 (1961).

\section{Rotational Analysis of ${ }^{65} \mathrm{Cu}^{35} \mathrm{Cl}$ Bands}

Aцtнолgн many extensive band systems are known for the CuCl molecule ${ }^{1}$, our knowledge of their rotational structure has been meagre. Apart from being heavy, natural cuprous chloride is a mixture of four isotopic species with not very different relative abundances. Very high dispersion and resolution are therefore needed to resolve, even partially, the rotational structure of the bands.

With the availability of compounds containing separated copper and chlorine isotopes, it has become possible to prepare copper chloride with any desired copper and chlorine isotopes. Milligram quantities of ${ }^{65} \mathrm{Cu}^{85} \mathrm{Cl}_{2}$ have been thus prepared and the spectrum of ${ }^{65} \mathrm{Cu}^{35} \mathrm{Cl}$ excited in an electrodeless discharge tube by a $2,450 \mathrm{mc}$./sec. Raytheon microwave oseillator ${ }^{2}$. All the known band systems of cuprous chloride were obtained with high intensity. The bands were photographed mostly in the fifth order of the Argonne National Laboratory 30 -ft. concave grating spectrograph (dispersion $0.3 \AA . / \mathrm{mm}$.). Bands for which rotational analysis has been done are given in Table 1 . Spectroscopic data obtained from the present work are given in Table 2. All values in this table, except those of $r_{e}$, are in $\mathrm{cm} .^{-1}$ units.

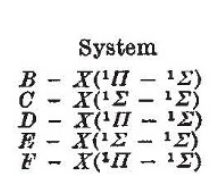

$$
\begin{aligned}
& \text { Table } 1 \\
& \text { Bands analysed } \\
& (1,0) ;(0,0) ;(0,1) \\
& (1,0) ;(0,0) ;(0,1) \\
& (3,1) ;(2,0) ;(1,0) ;(0,0) ;(0,1) ; \\
& (3,0) ;(2,0) ;(1,0) ;(0,0) ;(0,1) \\
& (3,0) ;(2,0) ;(1,0) ;(0,0) ;(0,1) ;
\end{aligned}
$$

